\title{
Atmospheres of stillness in Bristol's Bearpit
}

\section{Michael Buser}

Keywords: atmosphere; ambiance; stillness; public space; non-representational theory; Stokes Croft

\begin{abstract}
This paper studies atmospheres of stillness in a contested urban public space known as the 'Bearpit'. The purpose is to provide a nuanced account of stillness and its relationship to atmosphere. Drawing on an ethnographic examination of the Bearpit, the paper finds that the positive and beneficial aspects of stillness can be found in unexpected and unconventional places. However, there is no single, unifying experience of stillness, but rather a plurality of 'stillings'. The paper highlights three forms of stillness distilled from study of the site - calmness, control and withdrawnness - and demonstrates how these modalities emerge from and contribute to the construction of atmospheres in the Bearpit. Moreover, these atmospheres have direct political consequences for those who take part in city life. The paper's contribution is found in the advancement of non-anthropocentric understandings of atmosphere and the development of stillness as a way of understanding city life.
\end{abstract}




\section{Introduction}

"I' $m$ in the Bearpit, in a shipping container, there's only so much ambience I can create" (Mandy ${ }^{1}$, trader)

This paper is about atmosphere and stillness in the St. James Barton Roundabout, a small public space in the city of Bristol (UK) known as 'the Bearpit'. Constructed in the 1960s, the Bearpit is representative of urban transport designs of the time which sought to improve roadway efficiency, mobility and safety by separating pedestrians from cars. In addition to the creation of a large roundabout, crossings were removed and pedestrians were diverted underneath the roadway via four interlinked tunnels which open onto a large, sunken open space area at the centre (Evening Post 1967a; 1967b; 1968). In the years following construction, this interior area of the roundabout became known as a site of illicit activities such as street drinking, drug trading, and violence (Bristol Post 2010; 2015). By the 1990s, the Bearpit was largely considered a derelict public space and received defensive treatments such as the installation of CCTV cameras, anti-graffiti paint and street furniture to inhibit rough sleeping ${ }^{2}$. In recent years a local community group has worked to improve the space and counteract decades of neglect. While the Bearpit maintains an edgy urban feel, the site has become more vibrant and convivial and is well used. Perhaps unexpectedly, the site has also developed into an important space for some to experience the positive and beneficial aspects of stillness such as peace and calmness (amongst other modalities of stillness).

\footnotetext{
${ }^{1}$ All interviewee names have been changed. Interviews were conducted from February to April 2014.

2 This discussion is based on interviews with directors of the Bearpit Improvement Group, a retired urban planner and designer with Bristol City Council who was involved with the original project, personal observation and newspaper accounts.
} 
The paper calls upon a multi-year ethnographic research programme seeking to examine shifts in atmosphere in public space over time. The project was guided by an interest in investigating the social and material contributions to the emergence of collective affects and to question the apparent stability or durability of ascribed place meanings. Atmospheres of stillness were identified and examined only after an extensive period of observation and engagement in the Bearpit. This included analysis of interview and photographic data as well as collaboration with a media artist and the production of a video collage. Further, while the affective atmospheres discussed here represent only a fragment of experience in the space, this narrowed interest is used to facilitate a deeper engagement with the concept of stillness and how it can be expressed via different modalities (Bissell and Fuller, 2011). In this paper, I call on affective atmospheres (Anderson 2009) as a framing device to examine how modalities and registers of stillness emerge and shape experience in urban public space. As Anderson and Ash (2015, page 34) point out, 'the concept of affective atmosphere has been a way to think about the diffuse, collective nature of affective life', expressing and exemplifying an important, yet often unrecognised condition of urban experience. Research on atmosphere commonly draws on non-representational concerns with the more-than-textual and practice-based aspects of everyday life (Lorimer 2005; Thrift 2008; Vannini 2015). Methodologically, this indicates a particular style and research orientation that draws inspiration from the performative (Dewsbury 2000), and embodied practices of everyday life (Latham 2003; Thrift 2008; Anderson and Harrison 2010; Vannini 2015).

Within the domain of urban studies, the paper draws on Ash Amin's (2008) appreciation of public space as an entanglement of the human and non-human. Amin argues that the physical and technical infrastructures of urban public space are intrinsic to 
what it means to be human, "part and parcel of the urban 'social', rather than as a domain apart with negligible or extrinsic influence on the modes of being human" (Amin, 2008, page 8). At the centre of this project is an ontology where humans are not the sole possessors of being but are instead "among beings, entangled in beings and implicated in other beings" (Bryant, 2011, page 40 emphasis in original). For the study of phenomenon such as affective atmospheres, this indicates a curiosity in the so-called 'background' and taken-for-granted of everyday existence (Vannini 2015, page 9).

The paper takes up these themes in the study of atmospheres of stillness in the Bearpit. Towards this objective, it seeks to provide a nuanced account of the plurality of stillness and its relationship to atmosphere. Drawing on Bissell and Fuller, I move beyond static understandings of stillness and in the direction of an "ontology of stillness in and of itself" (2011, page 11). The paper further contributes to understandings of stillness by developing three modalities or forms of stillness - calmness, control and withdrawnness each of which surfaced as conceptual themes through research and engagement with the site. The narrative calls attention to the ways in which these modalities emerge from and contribute to the construction of atmospheres and how they mediate particular ways of being in and with the city.

The structure of the paper is as follows: in the next section I outline and summarise writing in geography and urban studies on affective atmosphere, positioning the concept within non-representational theory and research methodologies. This is followed by a discussion of recent geographic thinking about stillness including efforts to engage with the concept outside of its common framing and relationship with movement. These perspectives are then applied to the study of atmospheres of stillness in the Bearpit. The 
paper concludes with reflections on the case and the promotion of a speculative, morethan-human mode of urban and spatial research and inquiry.

\section{Exploring atmospheres}

Atmosphere is now an important concept in spatial research and analysis.

Geographers and urban scholars have deployed atmosphere (and the related concept of ambiance) to think through myriad phenomena including the affective sensations associated with the production of place (Duff 2010), mobility (Bissell, 2010; Lin, 2015; McCormack, 2008); the mega-city (Adey, 2013), surveillance (Adey et al, 2013; Ellis et al, 2013), public space (Koch and Latham, 2011), street performing (Simpson, 2013), English Football (Edensor, 2015), illuminated space (Edensor, 2012), the role and 'sensory production' of urban life (Thibaud, 2015, page 39), as well as in the relationships between non-human things (Ash, 2013) among other phenomena.

In much of this work, atmosphere provides a 'middle' or an in-between status by shifting between what is both singular and collective in experience and by disrupting subject/object distinctions. For Böhme, atmospheres possess an "intermediary status... between subject and object" (1993, page 114). Relatedly, Thibaud argues that the "pervasive quality' of urban atmospheres means that they are always perceived from within (2011, page 205; see also Thibaud 2015) and thus challenge nature-culture binaries. Specifically for the study of public space, atmosphere offers a way of thinking about the "swirl...of relational intensities" experienced out in the world (Koch and Latham, 2011, page 522). These intensities and experiences cannot be reduced to a singular body but can provide insights into meaning-making and human subjectivity. In this sense, atmosphere is the state of affairs or actualisation of a particular spatial-temporal condition - be it lively, dangerous, 
peaceful and so on. Such conditions, as Koch and Latham suggest, can "mobilise or cohere the sort of exchanges that take place" $(2011,523)$. While this disciplinary role of atmosphere does not entirely determine action, it nonetheless contributes to the regulation of behaviour, including how spaces are used, what is considered to be acceptable behaviours (Boyer, 2012). For example, particular ambiances (e.g. the excitement of a stadium or the calmness of a museum) can inform and mediate human agency and movement 'by placing us in a particular physical and emotional state' (Thibaud, 2011, page 209). In this sense, atmospheres are expressions of particular shared or collective forms of being and moving with the world. Nevertheless, while atmospheres may be palpable, shared and seemingly durable affective sensations, they are always open to transformation. For Dereck McCormack, atmospheric thinking can only ever muster a 'partial enclosure' $(2014,609)$. As such, our stories and accounts of atmospheres must be seen as circumstantial, as a call and response to 'the circumstances, properties and relations of the thing' (Adey, 2015, page 63; McCormack, 2014).

Much of the recent engagement with atmosphere has drawn inspiration from nonrepresentational and more-than-human perspectives (Anderson and Harrison, 2010; Thrift, 2008) where the effects and actions of the non-human world take on important explanatory roles (either alongside or in place of language and subjectivity). In addition to an interest in the agency of matter, this work commonly demonstrates a de-emphasis on humanism and associated traits such as reason, interpretation and meaning-making and a rejection of Cartesian ontologies that separate mind and body (replaced with a view that sees these as inextricable). Further, studies of atmosphere cohere to wider non-representational concerns with the everyday, unnoticed and background of urban experience. From this perspective, atmosphere provides a frame through which to more richly examine the 
sensory makeup of the world (Thibaud 2011), and the non-trivial relations between urban environments and the everyday, lived experience of urban inhabitants. For the study of urban public space, this includes attention to the 'mundane moments and background processes' (Thibaud 2015, page 49) that give consistency to affective atmospheres and ambiances.

\section{Unstilling stillness}

Stillness is a relatively unexplored area of focus in studies of atmosphere with most geographic work coming from the perspective of mobility studies (c.f. Adey, 2006; 2008; 2011; Bissell, 2007; 2009; 2011; Bissell and Fuller, 2011; Creswell, 2006; Urry, 2007) and health geographies (c.f. Conradson, 2005; 2011; Duff, 2011; Williams, 2007). From the perspective of health and wellbeing, stillness is often seen as a particular psychological state or condition of calm where an individual is attuned to the immediacy of a situation and "more aware of their immediate, embodied experience" (Conradson, 2007, 33). Such favourable experiences are often found by engagement with 'therapeutic landscapes' (Williams, 2007) including places of retreat and other settings where people can find solitude and diversion from the rhythm of everyday lives (Conradson, 2005). Yet, as Duff argues, the actual healing properties of such places are not stable 'but remain relational achievements' $(2011,155)$. Indeed, individuals will experience these environments differently. Moreover, therapeutic experiences are not exclusive to traditional places of retreat and can occur across a range of sites and durations (Conradson, 2005; Duff, 2011).

Yet, stillness is not always understood by this desirable, calming state. For example, within the context of neoliberal capitalism, mobility commonly takes precedence to 
stillness, which can be seen as both morally dubious and a personal weakness. As Bissell and Fuller note:

"where post-industrial, neo-liberal capitalism assures pride in the achievement of doing harder, better, stronger, faster, stillness is toxic: a failure of self-management, a resistance, a dragging of one's heels, a choking sullenness that flies in the face of the infectious pull of the world" (Bissell and Fuller, 2011, page 7).

This priority of the mobile reflects what Bissell calls a "productivist" depiction of the dialectics of mobility/immobility where economic reasoning is primary and where "it is always 'better' to be mobile than immobile" (2007, page 280).

Movement is also primary in many of our conceptual understandings of the world. Indeed, it is now commonplace to highlight the way place is constructed through multiple and dynamic connections, flows and processes of relation (Massey, 2005). "Space is never still" as Peter Adey notes (2006, page 90). However, without seeking to undo the insights gained by relational understandings of the world, Bissell and Fuller ask what are we missing when everything of importance is either in motion or explained through its relation to mobility. This is not to argue for a return to notions of spatial fixity, or a "sedentarist metaphysics" (Cresswell, 2006, page 26), but to see stillness beyond the frame of mobility/immobility. This understanding of stillness in-and-of-itself embraces a view where multiple forms of stillness (e.g. peaceful, calm, tense, anxious, unsettling, haunting, etc.) might be uncovered. This unstilling of stillness challenges the primacy of the body in motion through receptivity to the capacities of stillness and corporeal states of inactivity to engender new relations (Bissell and Fuller, 2011; Harrison, 2009). 
Nevertheless, within geography and associated disciplines, empirical work that challenges productivist understandings of stillness remains relatively limited. David Bissell's research on mobility stands out as a durable encounter with the intricate and diverse ways in which stillness pervades and shapes travelling experiences. For example, his study of railway travel (2009) examines the way being-still and quiescent emerges within and in concert with the confines of the train carriage. Bissell finds that such quiescence consists of both desirable as well as unpleasant or distressing experiences and points to the how these experiences impact and affect the body in different and sometimes long-lasting ways. In addition, the collection of essays within Bissell and Fuller's Stillness in a Mobile World develop stillness as a multiplicity where to be "[s]till is not a state or place of escape" (2011, page 13). Here, stillness is a force that contributes to the way the public realm is experienced and potentially disrupted (Cocker, 2011). However, as Adey (2011) cautions, stillness is composed of a range of intensities (e.g. anxious or calm) that fluctuate and course through particular fragile durations. In this paper, I take up these understandings in the examination of atmospheres in public space. To see atmospheres of stillness in this way means to be attentive to a spectrum of possibilities and to examine how stillness might emerge through unusual or unexpected configurations and display productive powers in its own right. The approach draws attention to non-pathological conceptions of passivity and stillness and challenges the central presuppositions of much contemporary work on the body where actions, doings and practices receive priority (Harrison 2009).

In the next section, I join together understandings of atmosphere and recent work on stillness to a study of the Bearpit. After introducing the project background and methods, I present the site context and key issues. Following this contextualisation, I highlight the emergence of affective atmospheres and draw attention to three particular modalities of 
stillness that were identified through the research process to contribute to everyday experience in the space.

\section{Atmospheres of stillness in the Bearpit}

The following empirical work originates from an ethnographic research project looking at affective atmospheres and place experiences in public space. This account draws primarily on a three-month period during which time I spent approximately 80 hours observing and participating in activity in Bristol's Bearpit. However, the work is also informed by a multi-year engagement with the space, the people and organisations involved with managing the site, artists, and those who frequent the space. Specific research methods were chosen to examine a wide range of possible relations and phenomena. These included observation and the use of field notes and diaries, time-lapse photography and filming, listening and audio recording, 52 interviews and numerous informal discussions with traders, commuters, passers-by, rough sleepers and members of the city's street culture (e.g. buskers and street drinkers) as well as an active personal engagement and participation in the space through arts interventions and collaborations with local groups. Analysis involved a thematic reading of the data including the production of an audio-visual output developed in concert with a graphic artist. ${ }^{3}$ Three modalities of stillness - calmness, control and withdrawnness - emerged over time through reflection on the interviews, visual material and personal field notes and experiences. While the research identified other affective atmospheres including those which resonated as chaotic, dangerous, lively, and so on, the focus on stillness represents an interest in exploring some of the taken-for-granted aspects of urban life and the urban background (Vannini, 2015). Further, expressions of

\footnotetext{
${ }^{3}$ Audio-visual collage: https://www.youtube.com/watch?v=KS7DOwz5Od0.
} 
stillness contradicted commonplace representation of the Bearpit as a place of fear and commotion and provided a frame through which to explore multiple modalities of being still. By centring on atmospheres of stillness, the paper seeks to make a commonly takenfor-granted aspect of the urban background more visible and to understand how these affects shape collective experience. This approach follows other recent studies in the arts, geography and the humanities as well as across much non-representational research where research methodologies are not seen as a means to 'capture' reality but rather, to "allow for ambiances and atmospheres to appear" (Adey et al, 2013, page 303).

Of course, these methodological decisions are implicated in the construction of social realities and I see myself as part of the construction of knowledge. To be a researcher in the Bearpit is to enact a particular set of material-discursive relations. It is to be an actor in particular materialisations, first through the identification and naming of particular atmospheres (Anderson and Ash, 2015) and subsequently by seeking to account for their durability and means of transformation. Such an approach recognises that we are never separate from these experiences. As Thibaud notes, 'we do not perceive the ambiance, we perceive on the basis of the ambiance' (2011, page 210). Ambiances and atmospheres are not the objects of perception but rather, they provide the frame through which we encounter and make sense of the world (Thibaud 2011). Thus, the following description should be seen as only one possible way of accounting for experience and phenomena in the Bearpit and not an endeavour to discern an ultimate truth. While the research includes accounts of traders, commuters, shoppers, passers-by, and vulnerable persons (including buskers, rough sleepers, as well as those who come to the Bearpit for food hand-outs), it remains centrally a first person narration framed by the author's regular interaction and engagement in the site. In other words, these atmospheric narratives of the Bearpit are 
'circumstantial' - accounts that are simultaneously uncertain, imperfect, and dynamic yet 'semi-bounded' and (temporarily) enclosed (McCormack, 2014, pages 609-610). While research tactics such as naming, narrating and explicating particular moments of everyday (affective) experience seek to give consistency to affective phenomena these accounts are never fully captured and remain open to other readings and the flux and dynamism of urban life (McCormack 2014). I now turn to my account of the Bearpit. The narrative begins with a brief contextualisation of the space followed by an exploration of atmospheres of stillness.

The Bearpit ${ }^{4}$

"there's nowhere else that has the Bearpit feel" (Pete, visitor)

“...broken glass, bottles, that sort of thing...people, sometimes you find people lying on the floor sort of unconscious..." (James, trader)

This study began at a time during which the Bearpit was undergoing a dramatic metamorphosis - a series of material and discursive changes set in motion by neighbourhood activists, community groups and, most recently, the city council. Much of this work sought to challenge a persistent culture of drinking, drug use and anti-social behaviour and the commonly held notion that the place was to be avoided. The Bearpit (Figure 1) is located in a busy area at the edge of the city centre shopping district adjacent to the city's bus terminal and surrounded by offices and hotels. To the north, it adjoins the neighbourhood of Stokes Croft, a trendy part of the city and burgeoning cultural quarter.

\footnotetext{
4 'Know Your Place' imagery available here: http://maps.bristol.gov.uk/kyp/?edition (type 'St. James Barton Roundabout' into address search)
} 
The Bearpit is a residual or leftover space within a larger system of motorway junctions, roundabouts, shopping precincts and parking structures. ${ }^{5}$ While the junction layout funnels thousands of pedestrians into and through a large open area, interviewees with longstanding knowledge of the site and newspaper accounts both suggest that the Bearpit has not historically been considered a pleasant place to linger by those on their way to and from work or shopping in the nearby city centre. Today, the site is an important gathering place for members of the city's street culture and is often occupied by street drinkers and rough sleepers. These are predominantly white (often middle-aged) men situated at the margins of society (e.g. they are often precariously housed and can suffer from addiction and/or mental health problems). The Bearpit has also been considered dangerous, especially for women and particularly at night.

Until recently, the Bearpit had not figured prominently in urban redevelopment strategies but has instead been the target of surveillance devices and technologies, urban design measures, and signage deployed to discourage drinking, drug trading, rough sleeping, and anti-social behaviour. These planning and urban design features contributed to an inhospitable urban environment designed to discourage lingering. However, since 2010, a local organisation of volunteers under the auspices of the Bearpit Improvement Group (BIG) has worked to change perceptions and redefine the site as a convivial public space (Shaftoe, 2008). The BIG is a Community Interest Company (CIC) made up by an equal mix of white men and women representing the local civic society, the university, local business (e.g. professional architects), neighbourhood activists (commonly associated with Stokes Croft), Bearpit traders, and other community-oriented interests. Examples of the group's improvements include new street furniture that actually encourages sitting and interaction,

\footnotetext{
${ }^{5}$ The site was not originally intended to be a public space. Original designs called for a limited access roadway directly through the space. This element of the project was never completed (Evening Post, 1967a).
} 
an outdoor art gallery and play activities (table tennis and chess), plantings of flowers and plants, bear sculptures and other whimsical and playful urban treatments (Figure 2). Arguably most central to this work, the BIG facilitated the creation of a market area with independent traders selling food and drink, clothes, paintings, second hand books, juggling and circus supplies and the like in a variety of temporary and quasi-temporary structures. While many of these structures were hand-built by traders, the coffee shop and fruit and vegetable sellers are located within two semi-permanent steel shipping containers.

Thus, since 2010, the Bearpit has demonstrated a growing sense of vibrancy and is increasingly considered a place where it is acceptable to sit and linger and enjoy being in the public sphere. Nevertheless, the site is still considered one of the more dangerous public spaces in Bristol, particularly by women (Bristol Post, 2016). The site has a noticeable Stokes Croft aesthetic, expressed primarily through clever graffiti and murals (Buser et al, 2013), and for some, is seen as a type of proving ground for first-time businesses, risk-takers, and experimental community arts activities. Many of those who trade in the Bearpit are former service sector workers, often from precarious backgrounds and economic conditions, seeking to develop their skills as cooks, bakers, salespeople and social entrepreneurs. Much of this activity can be described as a process of maintenance over time, or 'installing an ambiance' through everyday mundane activities of care and upkeep (Thibaud, 2015, page 44). Nevertheless, while these activities and their resonance often remain part of the urban backstage - unseen and unnoticed - they are central to the quality of the public realm (Amin, 2014).

Having now laid out a background to the site, in the following section I turn to an account and examination of atmospheres of stillness. Following Bissell and Fuller (2011), I challenge commonplace framings of stillness with the dialectics of speed/slowness and 
mobility/immobility. After a brief introduction, the narrative turns to an examination of three modalities of stillness - calmness, control, and withdrawnness.

\section{An introduction to stillness in the Bearpit}

"You know there's a certain stillness and quietness that is peaceful and then there's a stillness and quietness that is a bit creepy. I think that's just how it is down here, you just notice these little things" (Mandy, trader)

Mandy's comment reflects an attentiveness and sensibility to atmospheres of stillness that is dynamic and multiple. She expresses awareness of the affective powers of stillness and how emptiness comes to the fore, often encompassed within sparring moments of anxiety/tension and calmness/relaxation. This awareness of atmosphere was not unique, as most interviewees spoke adeptly and creatively about specific and often fleeting ambiences. Often, these ambiances were expressed in terms of calmness, peace and security. For example, another interviewee who had previously slept rough in the Bearpit commented on particular comforting aspects of the site.

“It feels safe...there's something with all the traffic going round, people going through, but it still feels secure" (Jane, visitor)

“... you know if you come down to the Bearpit you are going to meet somebody that you know...you get the comfort of the same people coming through..." (Jane, visitor) 
As a vulnerable individual in Bristol, Jane finds comfort and security in the Bearpit. Jane is a somewhat exceptional woman in that she is comfortable being in the Bearpit alone, even at night. Indeed, her participation with and comfort within the Bearpit belies the dominant order and condition of the Bearpit as a male space. She is a familiar face amongst the area's street community as well as local traders and is known for dancing solo in public to music playing on her headphones. However, stillness and security in the Bearpit are not fixed. Both Mandy and Jane explained how atmospheres of stillness could be easily disrupted, often by the introduction of a new body or a shift in the qualities of the space. This shift might be instigated by a single passer-by whose body interferes with their sense of tranquillity and co-constructs a new atmosphere. It could also be a shift in the flow of traffic surrounding the site or a sudden change in the weather (e.g. an increase in wind or dark clouds looming). In each of these cases, stillness previously understood as peaceful and calm, is changed qualitatively. It is filled with an uncomfortable tension expressed through particular bodily actions and, at times, a sense of entrapment. As Mandy explained, the 'peaceful' and cosy confines of the Bearpit can quickly shift to a 'creepy' atmosphere of enclosure and vulnerability. Jane expressed a similar idea about comfort and peace built around the presence of familiar and not-so-familiar faces. Like Mandy, she found the absence of people during the mid-morning and the general stillness of this time to be 'dead' and somewhat ominous. Yet, even quite small changes in the makeup of the space (e.g. the appearance of a single individual) could quickly transform affective resonances. These reflections point to the possibility of multiple modalities and registers of stillness and how stillness is not simply the absence of movement. Rather, atmospheres of stillness are (somewhat paradoxically) active, even disruptive and enmeshed in the forging of connections. Furthermore, these shifts lay bare the possibility of overlapping or the 
coexistence of atmospheres (Anderson and Ash, 2015). For example, precise moments of calm and peace for Jane might simultaneously resonate as creepy for Mandy. From relative positions of vulnerability and authority, these individuals experience the space and its atmospheres in dramatically different ways. Indeed, multiple atmospheres of stillness can coexist in the same public space without becoming fused or totally encompassing.

\section{Calmness: Bearpit as cocoon}

On the surface, it might seem difficult or contradictory to refer to the Bearpit as a cocoon, or a place where one might go in order to focus the mind or experience calming mental rhythms (Conradson, 2011). However, in spite of periodic outbreaks of violence and the swirl of vehicular movement encircling the site, one commonality among those interviewed was an expression of stillness, peacefulness and calm when describing their time in the Bearpit (as a participant and observer of this space, I also felt this type of focusing of consciousness). Consider the following excerpt of a discussion with James who runs a used bookstall:

James: “I think it's a place where people can relax...you know...people can sort of, you know they feel like they're not in the middle...of the metropolis and it's a bit of a still space I think."

Author: "Still?"

James: "Yeah, yeah, a calm place in the middle, with everything going on. You've got the roundabout going round you. It's like a, it's like, it's like a lake."

Author: "It's like a lake?"

James: "Yeah, yeah, in the middle, in the middle of everything going on in the busy city, that's the way I feel about it." 
James' lake metaphor calls forth a still, serene environment which contrasts not only the hardscape of the site but also the commonly-held assumptions about the Bearpit as a site of dereliction and chaos and a place one would be wise to avoid (Bristol Post, 2010a; 2010b; 2012; 2015). According to a long-time resident:

“Growing up it wasn't particularly safe... it's not a place you really came to and you were told to keep away from it as a child." (Mark, visitor)

However, in our discussion, the same individual went on to note how the space had changed and become more sociable and welcoming in recent years. Indeed, in James' account (above), he juxtaposes the hubbub of the city with the relative calm of the Bearpit. Later in the conversation he notes how the site's circular shape, its subterranean position and physical separation from the world above, its quirky non-conformist and independent shops, all contribute to a calming rhythm and atmosphere which contrasts the hypermobility of the ever-present city.

“...all the cars rushing round on the outside, people rushing around outside, it's just, I suppose it's because I'm always quite still in here I feel like that, I like to sit and watch everything go by..." (James, trader)

This is stillness inhabited by a purposeful desire to centre the mind and to experience the calmer mental rhythms associated with meditation and relaxation. Similar to those who meditate at more traditional places of retreat, James is enmeshed in the production of stillness with the Bearpit. He has shifted his attention from elsewhere to the present moment (Conradson 2011). Other interviewees expressed similar positive and calm 
emotional states when reflecting on their experiences in the Bearpit with the bulk of these expressing feelings of peace, restoration and comfort.

"it's a peaceful area in the midst of the mayhem of the city" (Andrew, BIG member)

"it's a place to relax." (Sue, visitor)

"it's an oasis in the centre." (Nancy, visitor)

"...most people that come to the Bearpit only want peace and quiet." (Jane, visitor)

"it's like being wrapped in a concrete blanket." (Matt, visitor)

During my research in the space, these (and similar) accounts of stillness were expressed by a range of urban-dwellers and users of the site. This included traders, passers-by as well as individuals associated with the area's street culture such as the homeless and street drinkers (the quotes above span this range). Of course, this peaceful expression of stillness is not uniformly experienced and what is calm and peaceful for a trader may be quite a different experience for someone who must sleep rough in the Bearpit. For some, this sense of peace was attributed to the subterranean separation of the Bearpit from the world above and the juxtaposition of an empty public space surrounded by flowing traffic and urbanised built form. Others noted the calming features associated with its quirky trading stalls, a few small pockets of green space, and the rhythmic movement of pedestrians from one tunnel to another. Finally, others noted that it was considered to be a safe space for rough sleeping. These examples suggest how atmospheres of stillness have become an important part of the background and flow of everyday life in the Bearpit, often felt as a type of containering. From this perspective, the peace and calm expressed by James and others is not a withdrawal or rejection of movement, but rather a cocooning by and within the city where multiple modalities of stillness emerge (Bissell and Fuller, 2011). Cocooning is thus a particular technique of stillness prescribed by and into the very fabric of the space. 
Of course, how this will be experienced by various urban inhabitants is never certain. Many of the individuals I spoke with - often, but not always women - expressed fear of the space (particularly at night) and regularly avoid the Bearpit. This suggests that any cocooning of/with the Bearpit and the capacity to experience stillness is always political and gendered.

\section{Control: stilling behaviour with non-humans}

Mandy and her colleague Trisha are traders in the Bearpit who spend the majority of their working days inside a shipping container fitted as a café (Figure 3). While the container is a site of trading and exchange, it is also a locus of regulation, an apparatus of surveillance and a mechanism of control. Within the container, Mandy and Trisha stand behind a counter in a position of authority surrounded by the accoutrements of the shop. The container is a lookout and a striation of urban space, forging atmospheres of stillness though techniques of discipline and control. Similar to many other objects in the Bearpit, it is a recent material intrusion and reflects an ongoing shift in relations between traders, street drinkers, homeless people, charity organisations and other site users. The structure was installed by the BIG to solidify trading opportunities, provide security and storage, and improve the site without generating significant city oversight (its capacity for movement and the potential 'mobility' of the shipping container means that it was treated as a temporary structure by the city council and not subject to planning permission).

Facing onto the site, the container (together with the 'civilized' practice of coffee drinking it houses) mediates how the site is disclosed and provides cues into the nature of acceptable activity. As part of an assemblage of control and surveillance the container challenges street drinking, anti-social behaviour, and regulates the nature of publicness (Németh and Schmidt, 2011) in the Bearpit (e.g. who belongs and what kinds of activities 
are acceptable). Many pedestrians and site users noted that the container and the presence of shop keepers makes them feel safer and has activated particular convivial notions of public space.

“...when the containers opened up, that was memorable...the whole perception finally flipped for me a hundred percent." (Matt, visitor)

“...if the book stall and the coffee shop in particular weren't there ... you would lose the people running them ... and then you would lose part of the family." (Jane, visitor)

Nevertheless, while the Bearpit has developed a cosy, quirky appeal, it can also be a space of vulnerability. Within the confines of the container and enclosed in a space that is set apart from the city, Mandy and her colleagues are exposed. In moments of disruption when there is a fight, or when someone is threatened by an individual with a knife - the Bearpit is no longer perceived as a space of calm or protection, but rather, it takes on the affective atmosphere of enclosure and entrapment. As Anderson and Ash (2015) point out, by reconfiguring the relations of bodies and affects, the introduction of new objects (e.g. in this case a knife) and behaviours can produce noticeable transformations in atmosphere. For Mandy, calm and peace is overcome or subsumed into an atmosphere of chaos and danger.

When Mandy and others talked about these occurrences, they often reflected on the lack of security and the limited options for escape (leaving a stall full of goods is not an option). Reflecting on these situations, traders noted how they commonly intervened and restored order, to still behaviour and reclaim atmospheres of calm and tranquillity. 
However, this was not an easy decision and these efforts were not always successful. Another trader reflected on a traumatic experience where he was unable to produce control:

“...one of the buskers was playing, Hotel California I think... and some of the lads just come round and smashed a glass in this guy's face and then mugged him. Some guy came round the corner ... and said [to me] 'why didn't you ring the police? I was like, 'look, I tried to ring the police'. He grabbed my phone and just threw it against the wall and smashed it into pieces. I was a little bit emotional so I started crying... I started crying in front of everyone. Not my finest hour. (Dave, trader)

In these moments, the materiality of the Bearpit takes on an active role in subjectification co-constructing how those who frequent and work in the space feel and understand a situation - and influencing how they act in the face of violence and danger. In the months following this unfortunate experience, Dave went on to take a significant role in managing diverse and clashing relations in the Bearpit by forging close connections with some of the more marginalised and vulnerable individuals who frequented the space.

Dave's transformation begins to show how these activities of control are not only framed by situational responses to immediate threat but rather can be seen as strategies and technics of stilling. To take another example, during the daytime homeless people, street drinkers, and charities are largely absent from the trading area. Some of the individuals who used to frequent this area have been asked to relocate to another part of the Bearpit, a few have received Anti-Social Behaviour Orders (ASBOs) and are legally restricted from the site, while others have simply decided to avoid the main trading area. In addition, fences have been erected to protect the area behind the containers where there 
are various trading materials as well as connections to water and power. Before the fences were put in place this area was a dumping ground for rubbish, served as a makeshift toilet and suffered a good deal of vandalism.

“I don't feel comfortable... behind the containers. It's just a bit run down and dirty... there's faeces and lots of garbage...If I have to go back there it's bad, something is bad" (Mandy, trader).

Jane, was similarly disturbed by the conditions behind the containers and has used the space as a toilet. However, as part of Bristol's street community, she was less enthusiastic about the fencing and noted:

'...the coffee shop leaves some of their bits and pieces ... coffee dregs and things, and it's not nice, it's wasted. It looks horrible, the bins and stuff... You've got the fencing up there, but people go around the back anyway'. (Jane, visitor)

The container and fences contribute to a wider set of practices that seek to contain behaviour and deny access. These are purposeful stillings of movement which work towards the production of particular (calmer) atmospheres and the stilling of (unwanted) bodies. Here, techniques of control and atmospheres of stillness attempt to fabricate acquiescence and compliance. To be still in the Bearpit is to submit to the (shifting) conventions of publicness. It is the forging of connections between bodies under conditions of presence - one must be still, adhere to the protocols of convivial space or be excluded, removed, or incarcerated (an even more extreme form of stillness). Yet, these are commonly resisted and bypassed, as Jane noted in the passage above. 
In this light, the traders' entanglement with the Bearpit means they are not only merchants but also connected to the production of atmospheres of stillness. In this role and in concert with the materiality of the space, they simultaneously contribute to safety, conviviality and exclusion by managing who belongs and who does not. This is not a universal experience of stillness. The most obvious implication of these efforts has been on the bodies and movements of those individuals associated with Bristol's street culture (e.g. the homeless, street drinkers). In some cases, particular expectations about behaviour and the so-called 'appropriate' modalities of stillness has led to animosity between site occupants (particularly traders and street drinkers) as well as moments of urban revanchism including the exclusion of individuals from the site via ASBOs and other forms of physical banning.

\section{Stillness withdrawn}

To this point, my account has remained largely concerned with human perspectives as I reflected on the way objects and the material world influenced human understanding and behaviour. However, must engagement with atmospheres always involve direct human sensory connection? What are the prospects for more-than-human atmospheres? Tim Flohr Sørensen (2015) takes up these questions in his study of Neolithic burial structures in southern Scandinavia (modern day Denmark) where he seeks to challenge subjectivist readings of atmosphere. Calling on the material culture of artefacts, architecture and his own bodily movements through the site's passage graves Sørensen narrates and gives life to atmospheres of prehistory and finds that these spaces were highly staged sites of burial and remembrance where the boundaries between living and dead were occluded. James Ash is 
similarly interested in de-subjectivist, more-than-human understandings of atmosphere. Reflecting on and speculating with the withdrawn components of a smart phone, Ash (2013) argues that objects only selectively interact or 'perturb' other objects and in the process of doing so, create particular (more-than-human) atmospheres. Elsewhere, Anderson and Ash suggest that by taking on a 'standpoint ontology' of the non-human, researchers can consider and 'think through how an object or force encounters other things' (2015, pages 41, 42). Engagements such as these provide clues and provocations for the study of atmospheres absent a conscious human perceiver.

These post-humanist perspectives are echoed in the work of object-oriented theorists such as lan Bogost (2012) and Levi Bryant (2011; 2014) where the boundaries between human and non-human, animate and inanimate are less decisive than in conventional social research and where speculative modes of inquiry are encouraged. In this section, I follow Bryant and this speculative scholarship in moving beyond the perceiving subject and further unpack 'stillness' by taking an object oriented approach in order to explicate the virtual and withdrawn nature of objects.

What happens when we take a step into the existence of material objects and ask 'what is it like to be a shipping container in the Bearpit?' For Bogost, to examine matter in this way requires a speculative means of inquiry and characterisation. We might ask questions such as: what is it that the container is doing in the Bearpit? How does the container experience its existence? Or, we might go further and speculate about the Bearpit itself? Anderson and Ash (2015, page 42) suggest that this attempt 'to occupy the standpoint' of non-human objects works as a 'flattening and breaking down of distinctions between various forms of living and dead matter' and allows researchers to think through the capacities and potential of more-than-human entities. In the case of the container, one 
response could be that the container is weighting and massing - a simultaneity of hunkering down (being still) and frontiering. Further portraying the experience, I might say that the object's steel frame and weight strains against the newly laid red lattice brickwork, pushing down and digging into the subterranean space of the Bearpit while it temporarily occupies a territory (taking on another form of waiting and being still). Putting myself into this scene I begin to imagine the points of connection between brick and steel.

To ask these questions and speculate about these experiences is to recognize already that we cannot possibly know - to seek access to an experience of stillness that is withdrawn. Bogost (2012) refers to this type of thinking as a process of caricature. Cognizant of an unavoidable anthropomorphism, Jane Bennett argues that to engage in such a processes is to move closer, not further from the non-human - "a chord is struck between person and thing, and I am no longer above or outside a non-human 'environment'” (Bennett, 2010, page 120). When interviewees discussed how the Bearpit could be understood as a cocoon or that it resembled a lake, they were using speculation and the imagination to forge a connection between themselves and the space. In this way, caricaturing and metaphorising (Bogost, 2012) the existence of non-human objects is a method for nurturing one's ability not only to identify material agency and the vitality of matter, but to speculate about how things enter into connections with one another outside the (human) perceiving subject.

Furthermore, when thinking of stillness, the convention is to reflect on a lack of movement within a dialectic of mobility/immobility. Indeed, calm moments in the Bearpit were often expressed during times when pedestrians were absent and 'things were quiet'. However, stillness is an active production. For example, calm or still weather (atmospheric stability) is not the absence of weather. Rather, it is a moment of equilibrium in the 
relationships between humidity and temperature. It is the actualisation of virtual powers expressed as qualities with particular affective tones which, in this case, resonate as 'still'. This line of reasoning can be seen in the work of Bogost and other object oriented thinking (e.g. Bryant 2011; 2014) where objects and things are capable of expressing qualities (and producing atmospheres) irrespective of human perception. Furthermore, these qualities are not possessive, they are not something objects 'have', but rather, are active realisations ('doings'). As such, rather than use the commonplace vernacular that the container is still, an object centred perspective might say that the container is 'stilling' or 'stills' (see Bryant, 2011, pages 89-90). Similar to the conditions of a stable meteorological atmosphere, the wider condition of the Bearpit stilling can be understood as a moment of equilibrium between various objects and qualities in the space. It is the coming together of a set of component parts - its circular shape, submerged position, the brick walls and asphalt, the weather, the movement of people and cars (and much more) - that produces atmospheres of stillness.

Yet, while we may physically encounter stillness, we never have access to this full potential. Rather, within every such encounter there remains something that is absent or withdrawn (see Harrison, 2009; Wylie, 2009). Corporeal engagement facilitates co-presence of self and Bearpit, making an individual aware or attuned to a particular atmosphere. However, there is always more. This perspective challenges purely relational explanations where everything of importance is said to be connected, fluid, in motion and in relation. Rather, for this Alien Phenomenology (Bogost, 2012), the appearance of continual interaction between entities (e.g. the production of particular atmospheres) is only evident because some aspect of these entities does not interact (Morton, 2013). According to Bryant, this withdrawal is generative of difference in the world. "Insofar as objects or 
substances alienate themselves...in qualities" he says "they are self-othering" (2011, page 85). In other words, the objects and things humans encounter are not identical to their qualities. Rather, they perpetually withdraw from their qualities. This thinking suggests that we come to know the atmospheres in the Bearpit not through what is present or at hand, but rather from what is withdrawn and kept in reserve - that which remains still.

\section{Conclusion}

The purpose of this study was to provide a nuanced account of stillness and its relationship to affective atmospheres. Drawing on recent non-representational thinking about atmosphere, ambiance and the background or taken-for-granted of everyday experience, the paper found stillness to be a strong component of urban life in the Bearpit. Following a brief discussion of the site, the paper highlighted three modalities of stillness calmness, control and withdrawnness. In line with Bissell and Fuller (2011), each modality was considered in-and-of-itself rather than exclusively within and readily packaged by the dialectics of mobility/immobility. The discussion explored how these modalities were perceived and understood and the force they exerted on practice and experience in the Bearpit.

One of the more surprising findings of the research was the emergence of the Bearpit as a place of calming and therapeutics. Time and again, traders, visitors and passersby reflected on the peaceful and calming nature of the site. For many people (at times including members of the city's street culture) the Bearpit is a space for reflection, contemplation and a centring of the mind. What is clear, however, is that these experiences of stillness are accomplishments and are not uniformly experienced by society (of particular 
importance in the Bearpit is time of day and gender). Nevertheless, that such experiences occur wholly encased in the urban fabric of a roundabout suggests that many more such spaces may exist. This discovery builds on the work of Duff (2010) and others who have documented the way people make use of the supposed unwanted and discarded spaces of the city.

However, atmospheres are not fixed and are always circumstantial (McCormack, 2014). As Mandy and Jane noted, calm and peaceful stillings could easily shift towards being 'creepy' and rendering them vulnerable and exposed. In these contexts, traders deployed particular techniques of surveillance and control towards the production of acquiescence and compliance to the norms of stillness in the Bearpit. The shipping container played a crucial role in this assemblage and was clearly non-neutral in the production of particular interpretations and the mediation of human actions. For the café operators, the container facilitated an engagement in and co-constitution of a wider assemblage and affective atmospheres of stillness and control. Through their collaborative actions, the Bearpit has become a safer and more pleasant place for many people to visit. This 'setting of ambiance' reflects the way atmospheres are put to work in urban sites and spaces (Thibaud, 2015, page 39) and influence the nature of urban experience. Yet, Mandy is effective in her control of the Bearpit only through connection with the shipping container. Further, this human-object collaboration has meaningful consequences for those marked as inappropriate or unwelcome. The most obvious manifestations are the physical barriers which restrict access and create areas of exclusion and stillness for unwanted bodies. Indeed, those individuals operating at the peripheries of society (such as the street drinkers who find comfort in the site) have found particular modalities of stillness to further limit their movement across the city. These findings point to the importance of 
understanding how the background, affective dimensions of the city and the mundane efforts of atmospheric design (Thibaud 2015) mediate and condition ways of being in and with the city.

These perspectives on daily life correspond with much of the geographical cannon regarding the production of space. For the human subject, these conditions reflect the "throwntogetherness" of public space and how the "coexisting heterogeneity" of varied elements connect the human and the non-human to produce a "here-and-now" (Massey 2005, pages 9 and 140). It is a multiplicity that makes the Bearpit what it is and how it is understood. Further, following Amin, it is the "entanglement between people and the material and visual culture..." and "the nature of the setting itself" $(2008,8)$ which influences how people react and respond to being in a communal space. Indeed, as the illustrations clearly suggest, any ability of urban public space such as the Bearpit to foster particular atmospheres cannot be located exclusively within human-human interaction. Finally, to understand the political stakes of transformations in and around public space one must take account of how these atmospheres both emerge from and contribute to everyday experience.

In the final empirical section, the paper looked beyond the frame of human-object relations and considered the experience of non-human things through the lens of withdrawnness. Central to this object oriented account was a flattening of existence and an equality of being amongst human and non-human objects. This is not to say that everything is the same. When Bogost claims that "all things equally exist" he goes on to clarify that "they do not exist equally" (2012, page 11). In other words, not only are objects irreducible to human encounter, neither (and perhaps more importantly) are they reducible to one another. This ontological framing points to a world that exists with and without humans 
and a reality that is not necessarily an expression of human experience and perception.

What the Bearpit is, is not what is perceived. It is an actualisation of powers, but we can never see the entire Bearpit or the entire container; there is always something in reserve. These qualities and characteristics are not the thing itself, but rather what it is doing. As such, to examine public space from an object oriented frame requires openness to speculative means of inquiry and characterisation. Indeed, when we begin to look at the existence of objects and object-object relations we resort to a process of caricature and anthropomorphising that, paradoxically, takes us closer to the vitality of matter. As Bogost suggests, it is an attempt to reveal objects, released "like ghosts from the prison of human experience" (2012, page 65).

To conclude, the focus of this paper has been on the mesh of objects, humans, and practices in the Bearpit which contribute to atmospheres of stillness. It provided two key scholarly contributions. First, it advanced non-representational research on affective atmospheres and the background of urban experience. Second, it progressed an account of stillness in-and-of-itself and developed three forms of stillness - calmness, control and withdrawnness - which were deployed to examine the production of atmospheres in the Bearpit. The analysis indicated that stillness is a crucial (if currently undervalued) way of making sense of urban experience. 


\section{Figures}

Figure 1: Location map (designed by Dhaval Hasmuclal)

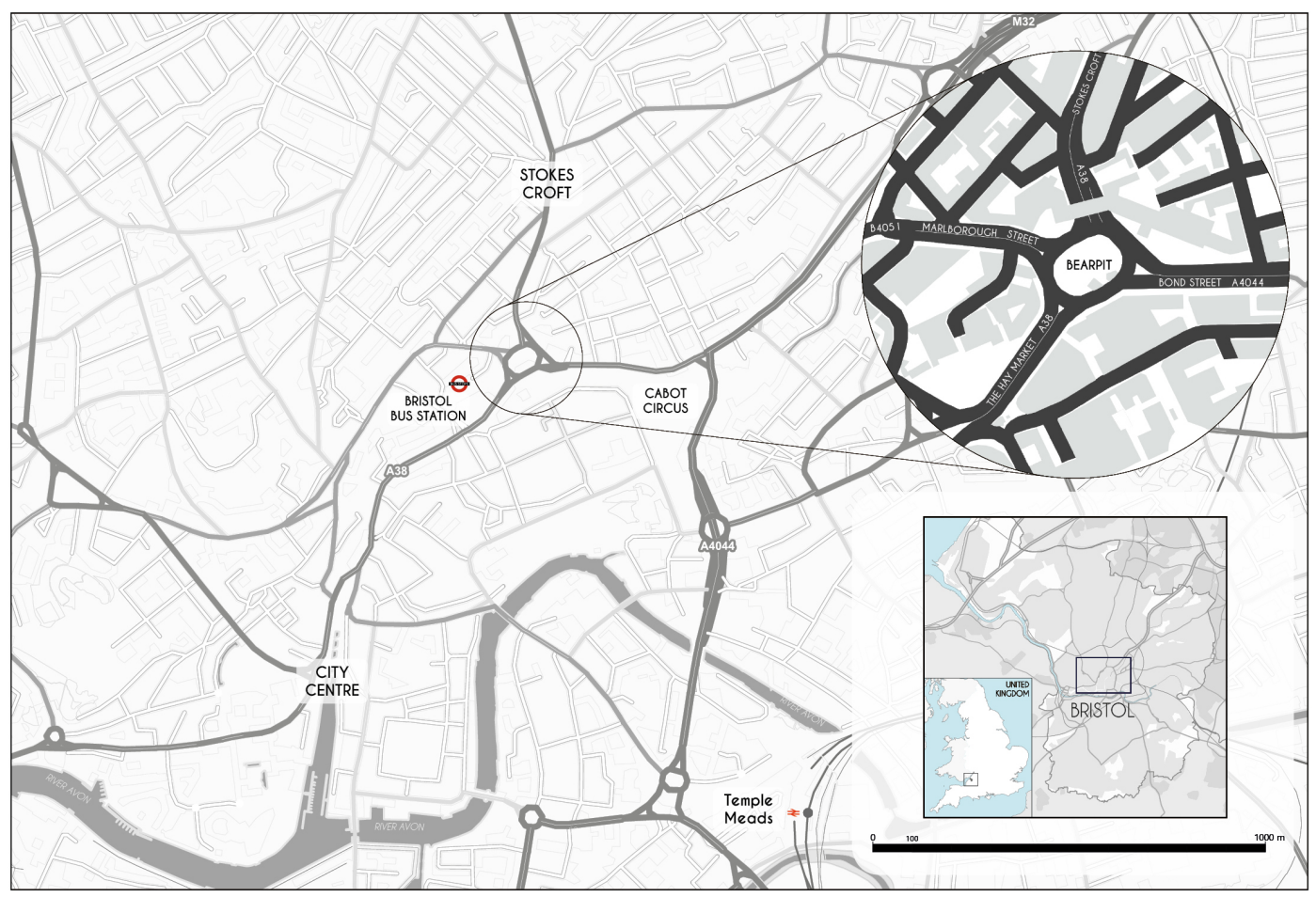

Figure 2: table tennis in the Bearpit. One of the recent playful additions to the site (image: author, February 2014)

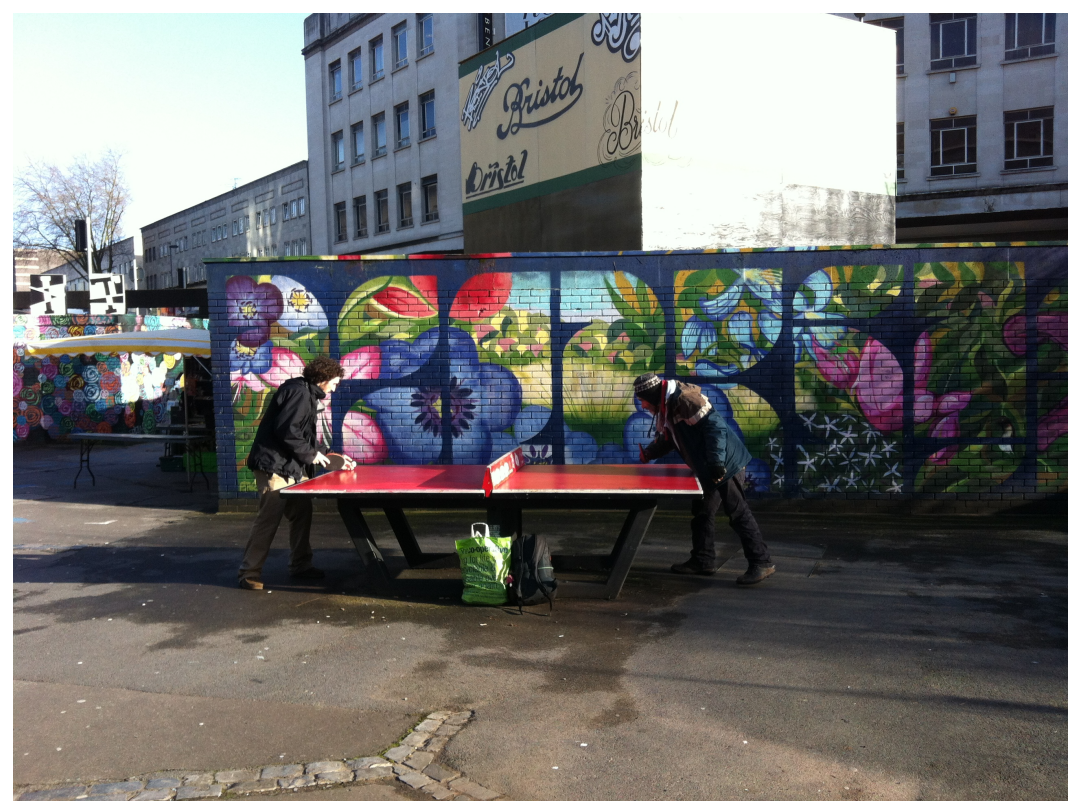


Figure 3: trading in the Bearpit. The container on the left is home to Mandy's coffee shop (image: author, February 2014)

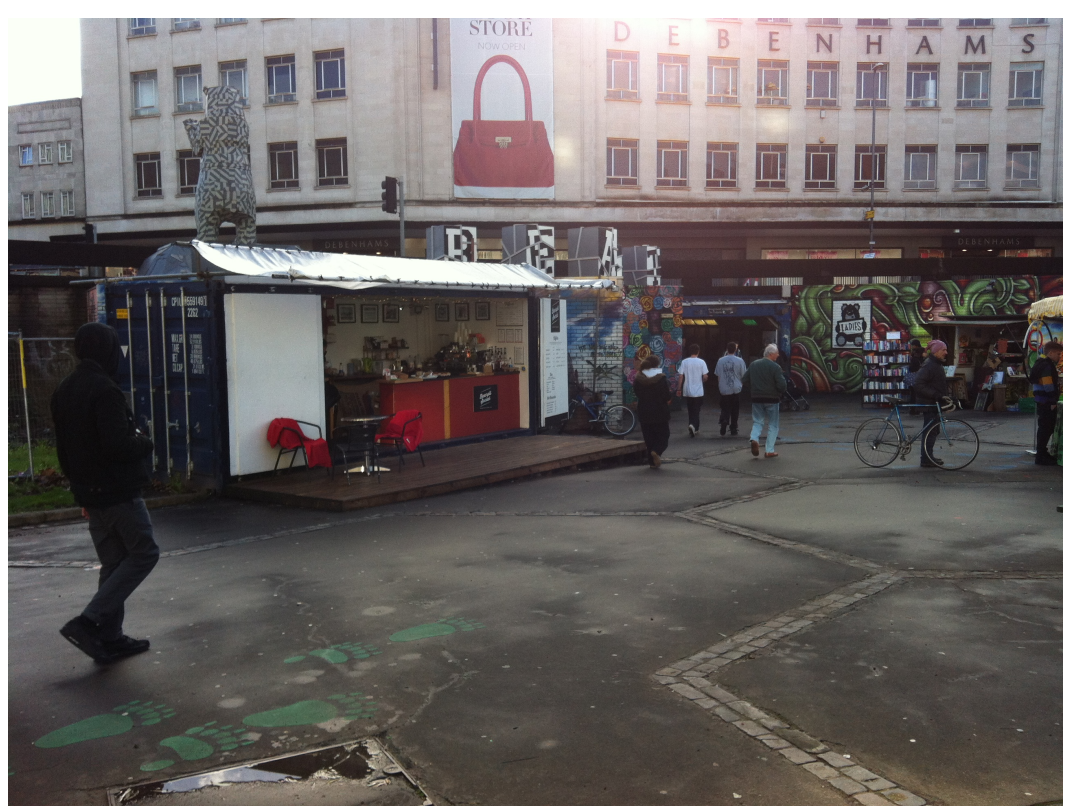




\section{References}

Adey P, 2006 "If mobility is everything, then it is nothing: towards a relational politics of (im)mobilities" Mobilities 1(1) 75-94.

Adey P, 2008, Mobility London: Routledge

Adey P, 2011 "The private life of an air raid" in Stillness in a mobile world Eds D Bissell, G Fuller (London: Routledge)

Adey P, 2013, "Air/Atmospheres of the Megacity" Theory, Culture \& Society 30(7/8), 291308

Adey P, 2015, "Air's affinities: Geopolitics, chemical affect and the force of the elemental" Dialogues in Human Geography 5(1) 54-75.

Adey P, Brayer L, Masson D, Murphy P, Simpson P, and Tixier N, 2013, "Pour votre tranquillité: ambiance, atmosphere, and surveillance" Geoforum 49 299-309.

Amin A, 2008, "Collective culture and urban public space" City: analysis of urban trends, culture, theory, policy, action 12(1) 5-24.

Amin A, 2014 "Lively infrastructure" Theory, Culture and Society 31(7-8) 137-161.

Anderson B, 2009, “Affective atmospheres" Emotion, Space and Society 2(2) 77-81.

Anderson B, Harrison P, 2010, "The promise of non-representational theories" in Takingplace: Non-representational Theories and Geography Eds B Anderson, P Harrison (Ashgate, London) pp 1-36

Anderson B, Ash J, 2015, "Atmospheric methods" in Non-Representational Methodologies: Re-Envisioning Research, Ed. P Vannini (Routledge, London) pp, 34-51.

Ash J, 2013, "Rethinking affective atmospheres: Technology, perturbation and space times of the non-human" Geoforum 49 20-28.

Bissell D, 2007, “Animating suspension: waiting for mobilities" Mobilities 2(2) 277-298

Bissell D, 2009, "Travelling vulnerabilities: mobile timespaces of quiescence" Cultural Geographies 16 427-445.

Bissell D, 2010, "Passenger mobilities: Affective atmospheres and the sociality of public transport" Environment and Planning D: Society \& Space 28(2) 270-289

Bissell D, 2011, "Thinking habits for uncertain subjects: movement, stillness, susceptibility" Environment and Planning A 43(11) 2649-2665.

Bissell D, Fuller G, 2011 "Stillness unbound" in Stillness in a mobile world Eds D Bissell, G Fuller (London: Routledge)

Bogost, I (2012) Alien Phenomenology, or What It's Like to Be a Thing (University of Minnesota Press: Minneapolis)

Böhme G, 1993, "Atmosphere as the fundamental concept of a new aesthetics" Thesis Eleven 36 113-126

Boyer K, 2012 "Affect, corporeality and the limits of belonging: breastfeeding in public in the contemporary UK" Health \& Place 18(3) 552-560 
Bristol Post, 2010a, "Plans to make Bearpit a little bit less grizzly" June 19, 2010 Available from: http://www.bristolpost.co.uk/Plans-make-Bearpit-little-bit-grizzly/story-11236869detail/story.html [accessed 05.05.15]

Bristol Post, 2010b, “Can big screen television tame Bristol's notorious Bear Pit?" October 26 2010 Available from: http://www.bristolpost.co.uk/big-TV-tame-Bear-Pit/story-11279956detail/story.html [accessed 05.05.15]

Bristol Post (2012) Bristol traders take up the challenge to transform the Bearpit. April 17 2012, available from: http://www.bristolpost.co.uk/Bristol-traders-challenge-transformBearpit/story-15837556-detail/story.html [accessed 05.05.15]

Bristol Post (2015) 19 things you may or may not already know about the Bearpit. June 2 2015 Available from: http://www.bristolpost.co.uk/19-things-know-Bearpit/story26619373-detail/story.html [accessed 05.05.15]

Bristol Post (2016) Revealed: Bristol's most dangerous streets. April 14 2016, Available from: http://www.bristolpost.co.uk/Exclusive-Bristol-s-dangerous-streets-revealed/story29111663-detail/story.html [accessed 02.05.16]

Bryant, L. R (2011) The Democracy of Objects (Open Humanities Press, Ann Arbor) Bryant, L. R (2014) Onto-cartographies: An Ontology of Space and Time (University of Edinburgh Press, Edinburgh)

Buser M, Bonura C, Fannin M, Boyer K, 2013, "Cultural activism and the politics of placemaking" City: Analysis of Urban Trends, Culture, Theory, Policy, Action 17(5) 606-627

Cresswell, T (2006) On the move: mobility in the western world. London: Routledge Dewsbury, JD, 2000, "Performativity and the event: enacting a philosophy of difference" Environment and Planning D: Society and Space. 18(4) $473-496$.

Duff C, 2010, "On the role of affect and practice in the production of place" Environment and Planning D: Society and Space 28(5) 881-895

Duff C, 2011, "Networks, resources and agencies: On the character and production of enabling places" Health \& Place 17(1), 149-156.

Ellis D, Tucker I, Harper D, 2013, "The affective atmospheres of surveillance" Theory \& Psychology 23(6) 716-731

Evening Post (1967a) How Bristol's big new roundabout will look. Evening Post. March 3 1967.

Evening Post (1967b) Giant road plan to beat jams. Evening Post. November 71967.

Evening Post (1968) A roundabout on the move. Evening Post. July 31, 1968.

Harrison P, 2009, "In the absence of practice" Environment and Planning D: Society and Space 27(6) 987-1009

Koch R, Latham A, 2011, "Rethinking urban public space: accounts from a junction in West London" Transactions of the Institute of British Geographers 37(4) 515-529 
Latham A, 2003, Research, performance, and doing human geography: some reflections on the diary-photograph diary-interview method. Environment and Planning A, 35 (11) 1993 2017.

Lin W, 2015, "'Cabin pressure': designing affective atmospheres in airline travel" Transactions of the Institute of British Geographers 40(2) 287-299

Massey D, 2005 For Space (Sage, London)

McCormack D, 2008, "Engineering affective atmospheres on the moving geographies of the 1897 Andrée expedition" Cultural Geographies 15(4) 415-530

McCormack D, 2014, "Atmospheric things and circumstantial excursions" Cultural Geographies 21(4) 605-625.

Morton, T, 2013, "Treating objects like women: feminist ontology and the question of essence" in International Perspectives in Feminist Ecocriticism, Eds. G Gaard, S C Estok, S Oppermann (Routledge, New York) pp. 56-69

Németh J, Schmidt S, 2011, "The privatization of public space: modelling and measuring publicness" Environment and Planning B: Planning and Design 38(1) 5-23

Shaftoe H, 2008 Convivial Urban Spaces: Creating Effective Public Spaces. (Earthscan, London)

Simpson P, 2013, "Ecologies of experience: materiality, sociality, and the embodied experience of (street) performing" Environment and Planning A 45(1) 180-196

Sørensen T F, 2015 "Towards an archaeology of atmosphere. Emotion, Space and Society 15 64-73.

Thrift N, 2008 Non-representational Theory: Space, Politics, Affect (Routledge, London).

Urry J, 2007, Mobilities. Cambridge: Polity

Vannini P, 2015, "Non-representational research methodologies: an introduction" in NonRepresentational Methodologies: Re-Envisioning Research, Ed. P Vannini (Routledge, London) pp, $1-18$.

Wylie J, 2009, Landscape, absence and the geographies of love. Transactions of the Institute of British Geographers, 34(3) 